\title{
Flammability action of tires material after adding flame inhibitor
}

\author{
Ali I.Al-Mosawi* \\ HaiderK.Ammash** \\ Mohammad H. Al-Maamori*** AbbassHashim****
}

Received18,October , 2012

Accepted 7, December, 2012

\begin{abstract}
:
Magnesium hydroxide was used as flame inhibitorto increased flame resistance fortires.Magnesium hydroxide was adding with $(5 \%, 10 \%)$ weight percents to rubber master batch of tire and then exposed the resulting material to a flame generated from gas torch with $(10 \mathrm{~mm})$ exposure distance. Method of measuring the surface temperature opposite to the flame was used to determine the heat transferred through tire material. The results were obtained shows enhanced flame resistance for tire by added magnesium hydroxide and this resistance increased by increasing hydroxide Percentage .
\end{abstract}

Keywords:Flame action, Magnesium Hydroxide, Tires material.

\section{Introduction:}

Magnesium hydroxide $\left(\mathrm{Mg}(\mathrm{OH})_{2}\right)$, is an acid- and halogen-free flame retardant for various plastics. Both hydroxides decompose endothermically when heated according to the reactions: $\mathrm{Mg}(\mathrm{OH})_{2}--->\mathrm{MgO}+\mathrm{H}_{2} \mathrm{O}$

The gaseous water phase is believed to envelop the flame, thereby excluding oxygen and diluting flammable gases [1] .Similar to the function of char formed by phosphorous containing flame retardants, a heat insulating material may form on the surface of the plastic in contact with the flame, reducing the flow of potentially flammable decomposition products to the gas phase where combustion occurs. In both of the reactions, the decomposition products are non-toxic and the mineral phases, especially $\mathrm{MgO}$, are alkaline, reducing the likelihood of acidic, corrosive gases exiting the plastic[2].

As a function of its purpose, an aircraft tire must withstand and a wide range of operational conditions. When on the ground, it must support the weight of the aircraft . During taxi, it must provide a stable cushioned ride while resisting heat generation, abrasion and wear [3]. When aircraft down, the tire may be fired because high friction with ground. Since plastics and rubber are synthetic organic materials with carbon and often high hydrogen contents, they are combustible. The objective in flame retarding polymers is to increase ignition resistance and reduce rate of flame spread [4]. One way to better protect combustible materials against initiating fires is the use of flame retardants, which are substances that can be chemically inserted into the polymer molecule or be physically blended in polymers after polymerization to suppress, reduce , delay or modify the propagation of a flame through a plastic materials [4].

There are several classes of flame retardants; halogenated hydrocarbons (chlorine and bromine containing compounds and reactive flame retardants): inorganic flame retardants 
(boron compounds, antimony oxides, aluminum hydroxide, etc); phosphorus containing compounds; nitrogen containing flame retardants. Depending on their nature, flame retardants can act physically or chemically [4]. Few inorganic compounds are suitable for use as flame retardants in plastics, since such compounds must be effective in the range of decomposition temperature of the plastic, mainly $\left(150^{\circ} \mathrm{C}-400^{\circ} \mathrm{C}\right)$. Inorganic flame retardants don't evaporate under the influence of heat ; rather they decompose ; giving off nonflammable gases like water, carbon dioxide, sulphur dioxide, hydrogen chloride, etc. mostly endothermic reaction . in the gas phase, these act by diluting the mixture of flammable gases and by shielding the surface of the polymer against oxygen attack [5] .

The inorganic flame retardants act simultaneously on the surface of the solid phase by cooling the polymer via endothermic breakdown process and reducing the formation of pyrolysis products. In addition, as in the case of inorganic boron compounds, a glassy protective layer can form on the substrate, fending off the effect of oxygen and heat [6] .As example to inorganic flame retardants is magnesium hydroxide, zinc borate, aluminum hydroxide, and antimony oxides .

Magnesium hydroxide $\left(\mathrm{Mg}(\mathrm{OH})_{2}\right)$, is a white powder, very slightly soluble in water, It is used in as flame retardant and smoke suppressant for plastics, synthetic rubber, reinforced polyesters, phenolics, and urethane foam. Magnesium hydroxide releases its $31 \%$ water when heated to above $\left(325^{\circ} \mathrm{C}\right)$, which cools the product below flash point to reduce fire occurance[7]. This hydroxide decomposeendothermically when heated according to the reaction:

$\mathrm{Mg}(\mathrm{OH})_{2}+$ Energy $\longrightarrow \mathrm{MgO}+\mathrm{H}_{2} \mathrm{O}$
The gaseous water phase is believed to envelop the flame, thereby excluding oxygen and diluting flammable gases. Similar to the function of char formed by phosphorous- containing flame retardants, a heat insulating material may form on the surface of the plastic in contact with the flame, reducing the flow of potentially flammable decomposition products to the gas phase where combustion occurs [7].

\section{Materials and Methods:}

1- Master Batch: There are eight types of materials employed in this study [8]:

- Natural Rubber (NR) : basic of batch .

- Zinc Oxide( $\mathrm{ZnO})$ : activator material .

- Stearic Acid (St.A): activatormaterial .

- Carbon Black (N-330): Reinforcing material .

- Sulfur (S): Vulcanization material.

- MBS : Accelerating material .

- DPPD : Anti oxidation and ozone material and thermal stabilizer .

- Resorcinol Formaldehyde Resin (RFR) :Increasing adhesive, creep and fatigue and Intumescent resistance ,and thermal stabilizer .

The weight percentages of materials in master batch are shown in Table.1. 
Table (.1): Weight percentages of materials in master batch

\begin{tabular}{|l|c|}
\hline Material & pphr \\
\hline NR & 100 \\
\hline ZnO & 5 \\
\hline St.A & 2 \\
\hline (N-330) & 35 \\
\hline S & 2.25 \\
\hline MBS & 1.2 \\
\hline DPPD & 1 \\
\hline RFR & 1 \\
\hline
\end{tabular}

2- Magnesium Hydroxide : was used as particles $(3 \mu)$ in size .This material was supplied from $(\mathrm{C}-\mathrm{Tech}$ Corporation) . Magnesium hydroxide was added to master batch with $(5 \%, 10 \%)$ weight percentages .

\section{3- Preparation of Test Specimens:}

Specimens of thermal erosion test are a square shape with dimensions (100 $\times 100 \mathrm{~mm})$, and $(10 \mathrm{~mm})$ thickness. All compounds of master batch and magnesium hydroxide were mixed in open mill working at $\left(70^{\circ} \mathrm{C}\right)$.This mixture result was pressed in square die with the same dimensions of thermal erosion specimens by a hot press working at (40 atm) pressure and $\left(170^{\circ} \mathrm{C}\right)$ which is found in company of tires industry -Babel .

\section{4- Thermal Erosion Test.}

Flamegeneratedfrombutane-propane gas $\left(\mathrm{C}_{3} \mathrm{H}_{8}-\mathrm{C}_{4} \mathrm{H}_{10}\right)$ withtemperature $\left(2000^{\circ} \mathrm{C}\right)$ was used in this test. The system (contains flame retardant material and composite material) was exposed to this flame under exposure distance $(10 \mathrm{~mm})$.

Fig.1 shows the thermal erosion test apparatus, surface temperature method used here to calculate the amount of heat transmitted through flame retardant material and composite material

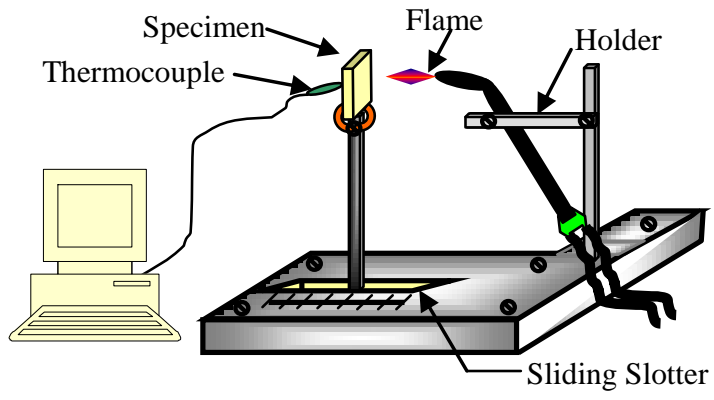

Fig (.1): thermal erosion test apparatus

Temperature monitoring and recording system (see Fig.2) was used to observe and save temperatures measured by thermocouple type $-\mathrm{K}$ by entering it in computers by transformation card (AD).

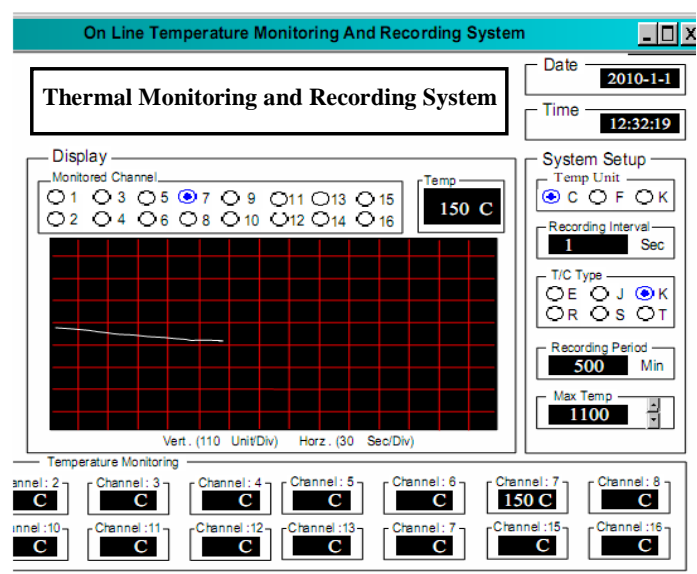

Fig(.2) : Thermal monitoring and recording system

\section{Results and Discussion}

Fig. 3 represents the thermal erosion test for tire material with $(5 \%)$ magnesium hydroxide, the temperature of the opposite surface to the torch begins to increase with increasing exposition time to the flame . During this stage, magnesium hydroxide has a water of hydration in its chemical structure, therefore, it released this water to extinguish the fire through cooling, in addition, magnesium hydroxide will formed char layer which protecting the substrate and the fire spread will decrease. 
Fig. 3 represents the thermal erosion test for tire material with $(10 \%)$ magnesium hydroxide. As a result, when the magnesium hydroxide increased to $(10 \%)$, the time necessary to break down of tire material increase and the combustion gaseous will reduced and there will be a less rubber to burn due to water of hydration and protected char layer comes from this hydroxide.

\section{Conclusions:}

From the obtained results we get :improvement flame retardancy for aircraft tires with added magnesium hydroxide. The resistance to flame spread will be increased with increasing magnesium hydroxide percentage .

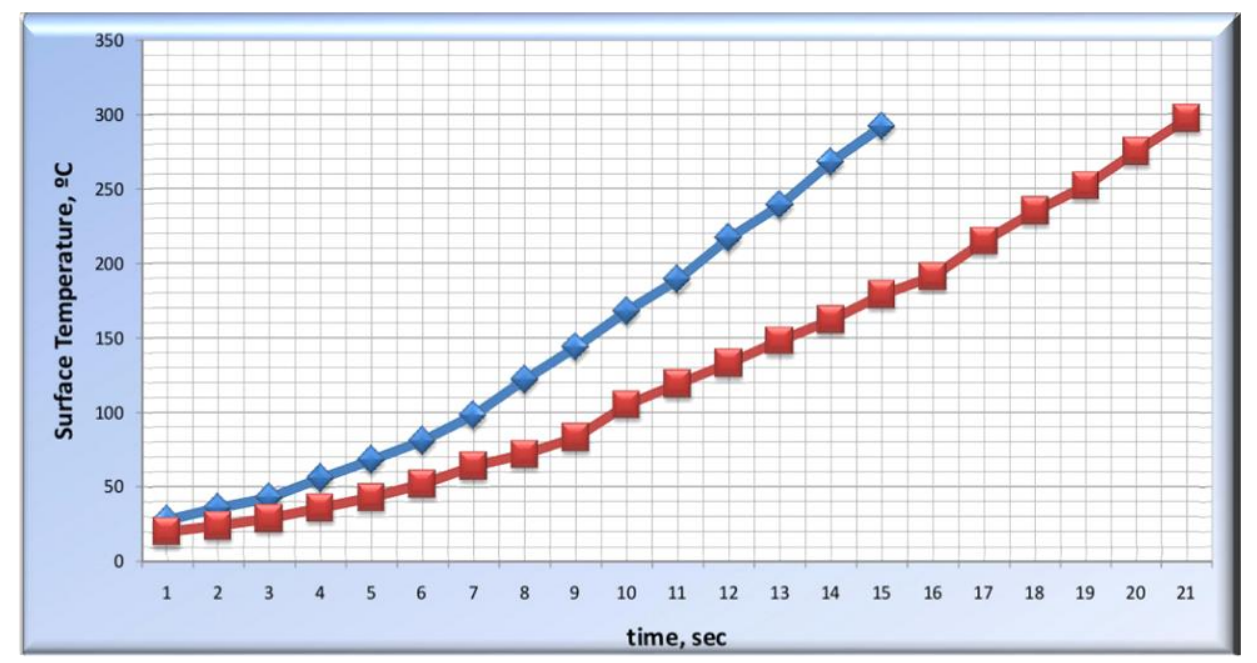

Fig (.3) : Thermal erosion test for tire material with $(10 \mathrm{~mm})$ exposure distance

\section{References:}

1- Ali I .Al-Mosawi, SalimJ.Abbas, Salimh.Flayah2012 .Influence of retardant agent on flame spread through composite surface, International Journal of Innovative Research in Engineering \& Science, 6(1):13-16 .

2- Michel Le Bras, Charles A. Wilkie, Serge Bourbigot, Sophie Duquesne, CharafeddineJama. Fire Retardancy of Polymers New Applications of Mineral Fillers , The Royal Society of Chemistry ,UK, 2005.

3- Michelin Aircraft Tire Corporation Aircraft tire engineering data, 2010.

4- HorrocksA.R., Price D. Advances in Fire Retardant Materials, Woodhe Io publishing in materials, 2008.

5- LevchikSV.Introduction to flame retardancy and polymer flammability. Morgan AB,
WilkieCA, editors, John Wiley \& Sons; NY, USA: , 2007 : 1-29.

6- LomakinS.M. and ZaikovG.E. "Modern Polymer Flame

Retardancy", New Concepts in Polymer Science, 16,Brill DisclaimerPublisher, 2003.

5- Jürgen Troitzsch.Plastics flammability handbook: principles, regulations, testing, and appro. $3^{\text {rd }}$ Edition , HanserVerlag Publisher ,2004.

7- Matthew D. Walter, Mark T. Wajer. Overview of Flame Retardants Including Magnesium Hydroxide . Martin Marietta Magnesia Specialties LLC ,2000 .

8- Mohammad H.Al-Maamori ,AudaJ.Brahi.Study the effect of kaolin in design of rubber batch for aircraft tires .Iraqi Journal for mechanical and materials Engineering , Special Issue, $1^{\text {st }}$ 
Conference of Engineering College 17-18 May 2009: 269-276.

فعل قابلية الإشتعال لمادة الإطار ات بعد إضافة مثبط للهب

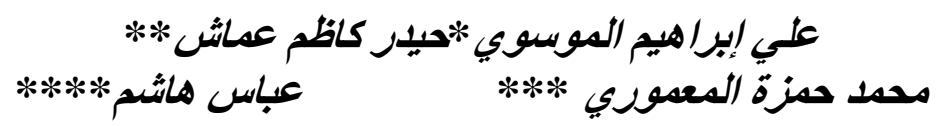

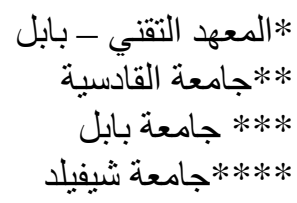

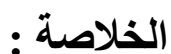

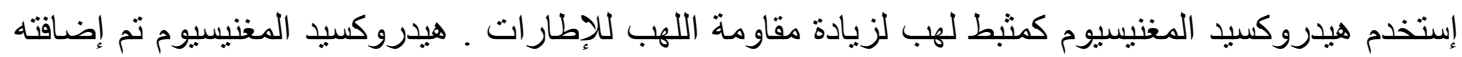

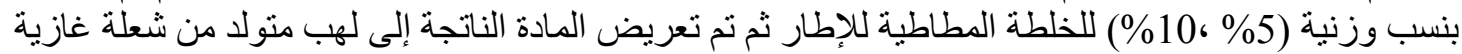

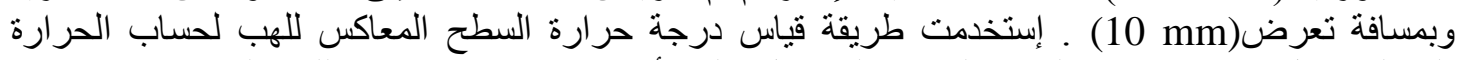

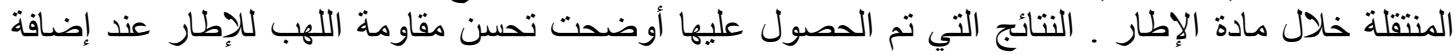

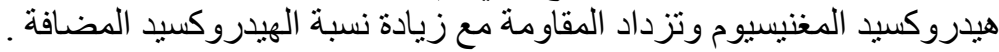

